\title{
Dmrt1, a gene related to worm and fly sexual regulators, is required for mammalian testis differentiation
}

\author{
Christopher S. Raymond, ${ }^{1}$ Mark W. Murphy, ${ }^{2}$ M. Gerard O'Sullivan, ${ }^{3}$ Vivian J. Bardwell, ${ }^{2,4}$ \\ and David Zarkower ${ }^{1,2,5}$ \\ ${ }^{1}$ Graduate Program in Biochemistry, Molecular Biology and Biophysics, ${ }^{2}$ Department of Genetics, Cell Biology, \\ and Development, ${ }^{3}$ Department of Veterinary Medicine and Pathology, ${ }^{4}$ Cancer Center, University of Minnesota, \\ Minneapolis, Minnesota 55455, USA.
}

\begin{abstract}
The only molecular similarity in sex determination found so far among phyla is between the Drosophila doublesex $(d s x)$ and Caenorhabditis elegans mab-3 genes. $d s x$ and $m a b$-3 contain a zinc finger-like DNA-binding motif called the DM domain, perform several related regulatory functions, and are at least partially interchangeable in vivo. A DM domain gene called Dmrt1 has been implicated in male gonad development in a variety of vertebrates, on the basis of embryonic expression and chromosomal location. Such evidence is highly suggestive of a conserved role(s) for Dmrt1 in vertebrate sexual development, but there has been no functional analysis of this gene in any species. Here we show that murine Dmrt1 is essential for postnatal testis differentiation, with mutant phenotypes similar to those caused by human chromosome 9p deletions that remove the gene. As in the case of $9 \mathrm{p}$ deletions, Dmrt1 is dispensable for ovary development in the mouse. Thus, as in invertebrates, a DM domain gene regulates vertebrate male development.
\end{abstract}

[Key Words: DM domain; Dmrt1; sex determination; doublesex; mab-3]

Received July 15, 2000; revised version accepted September 6, 2000.

In contrast to many developmental processes, for example, body axis establishment or segmentation, genetic and molecular analyses of sex determination have revealed virtually no clear evolutionary conservation between phyla. A potential exception to this lack of conservation is the similarity of the Caenorhabditis elegans mab-3 gene (Shen and Hodgkin 1988) and the Drosophila dsx gene (Baker and Ridge 1980). These genes share a number of properties, suggesting that some mechanisms controlling sexual development may be conserved between nematodes and arthropods (Raymond et al. 1998). Both genes contain the DM domain, a zinc finger-like DNA-binding motif (Erdman and Burtis 1993; Raymond et al. 1998). Functionally, the two genes are also related in several respects: Both directly regulate yolk protein gene transcription (Coschigano and Wensink 1993; Yi and Zarkower 1999|, both are required for differentiation of male-specific sense organs (Baker and Ridge 1980; Shen and Hodgkin 1988; Yi et al. 2000), and both mediate male mating behavior (Villella and Hall 1996; Yi et al. 2000). Furthermore, the male-specific isoform of $d s x$, but not the female-specific isoform, can replace $m a b-3$ in vivo (Raymond et al. 1998).

${ }^{5}$ Corresponding author.

E-MAIL zarkower@gene.med.umn.edu; FAX (612) 626-7031.

Article and publication are at www.genesdev.org/cgi/doi/10.1101/ $\operatorname{gad} .834100$.
DM domain genes have been implicated in vertebrate sexual development by chromosomal location and by embryonic expression. Human DMRT1 maps to an autosomal locus $(9 \mathrm{p} 24.3)$ that, when hemizygous, is associated with defective testicular development and consequent 46,XY feminization (Crocker et al. 1988; Hoo et al. 1989; Bennett et al. 1993; Veitia et al. 1997, 1998; Flejter et al. 1998; Guioli et al. 1998; Raymond et al. 1998). In birds, which have ZZ/ZW sex determination, Dmrt1 is found on the $Z$ chromosome (Nanda et al. 1999), again suggesting that two doses of Dmrt1 ( $\mathrm{ZZ}=$ male) might be necessary for testis development. In all vertebrates examined, Dmrt1 is expressed in the differentiating male genital ridges and adult testis, including mammals, birds, and reptiles with temperature-dependent sex determination (Raymond et al. 1999a; Smith et al. 1999; De Grandi et al. 2000; Kettlewell et al. 2000; Moniot et al. 2000). In most vertebrates, including humans, Dmrt1 expression is higher in genital ridges destined for testis differentiation, starting very early in development, suggesting a likely role in male sex determination or in later testis differentiation. In mouse, Dmrt1 mRNA is expressed in the genital ridges of both sexes and then becomes testis specific at the end of the sex-determining period. This expression is consistent with a sex-determining role in either sex, or with a later role in testis differentiation, or both. 
Taken together, the expression profiles and chromosomal locations of Dmrt1 in different species strongly suggest that it plays a conserved role(s) in vertebrate male gonad development. However, no functional data have been reported from any vertebrate. To test the role of Dmrt1 in a mammal, we have generated a deletion allele of the murine Dmrt1 gene. We find that Dmrt1 is required for multiple aspects of testis differentiation and is not required for ovary development.

\section{Results and Discussion}

\section{Targeted deletion of Dmrt1}

We generated a targeted deletion in the murine Dmrt1 gene using the strategy diagrammed in Figure 1A. Because the DM domain is essential for function of MAB-3 and DSX (Shen and Hodgkin 1988; Erdman and Burtis 1993; Raymond et al. 1998), we removed the exon encoding this domain of Dmrt1, plus the predicted transcriptional start site and part of the first intron (Fig. 1B). Transcription from the mutant allele is greatly reduced, although a low level can be detected by RT-PCR (Fig. 1C). On the basis of cDNA sequencing and analysis of $5^{\prime}$ RACE products (data not shown), the deletion removes the major transcriptional start site and $\sim 300$ bp of promoter sequence, so the remaining RNAs presumably originate from a minor upstream start site. Because these transcripts lack the DM domain, they should not be able to encode a functional Dmrt1 protein. In addition, immunohistochemistry (described below) demonstrates that the mutant allele does not express detectable Dmrt1 protein. This deletion mutation, Dmrt1 ${ }^{-}$, therefore appears to be a null allele.

\section{Dmrtl is required for testis but not ovary differentiation}

The Dmrt1 $1^{-}$mutation causes severe defects in the adult testis (Fig. 2). Although heterozygous Dmrt1 $1^{+/-}$males have normal testes (Fig. 2A,B) and are fertile, homozygous $D m r t 1^{-/-}$mutants have severely hypoplastic testes (Fig. 2A). Microscopic examination reveals that Dmrt1 $1^{-/-}$ seminiferous tubules are disorganized and germ cells are missing (Fig. 2C,D; see legend for details). There is evidence of fatty degeneration of interstitial (Leydig) cells with infiltration by macrophages. No ectopic ovarian tissue or Mullerian duct-derived structures are apparent in Dmrt1 ${ }^{-/-}$males. Thus, the murine Dmrt1 null phenotype, like that of human 9p monosomy (Ogata et al. 1997; Guioli et al. 1998; Ion et al. 1998; Veitia et al. 1998), is a failure of testis differentiation, accompanied by germ cell death, rather than a transformation of testis to ovary. Although Dmrt1 mRNA is expressed in the XX genital ridge during early gonadal development, XX Dmrt1 $1^{+/-}$and Dmrt1 ${ }^{-/-}$mutant mice, like XX humans with 9p deletions, have normal ovaries and are fertile (data not shown). This indicates either that Dmrt1 does not function in ovary development in the mouse or that any role it plays is functionally redundant.

\section{Pre-meiotic germ cell death in Dmrt $1^{-/-}$mutant testes}

Testis development can be divided into three stages as follows: formation of the undifferentiated or indifferent gonad; commitment to testis rather than ovary development; and differentiation into a functional testis. Clearly, testis differentiation is severely defective in Dmrt1 $1^{-/-}$mutants. To determine when defective testis development begins, we examined earlier stages. Prior to postnatal day 7 (P7), Dmrt1 ${ }^{-/-}$testes appear grossly normal relative to $D m r t 1^{+/-}$littermates (Fig. 3A,B; data not shown). However, by P10, just after meiosis normally begins, germ cell numbers in Dmrt1 ${ }^{-/-}$testis are greatly reduced (Fig. 3C,D). Levels of apoptosis appear normal in Dmrt1 $1^{-/-}$testes (not shown), so this may represent re-

Figure 1. Strategy for producing the Dmrt1 deletion mutant. (A) Diagram of Dmrt1 wild-type and mutant alleles. Homologous recombination of the targeting vector with the wild-type Dmrt1 allele $\left(D m r t 1^{+}\right)$resulted in the loxP-flanked (floxed) allele Dmrt1 $1^{\text {neo }}$. This allele also contains within the first intron a neomycin-resistance cassette $(P g k-n e o)$ flanked by Flp recombinase recognition sites (frt sites). Mice heterozygous for the Dmrt $1^{\text {neo }}$ allele were mated with transgenic mice expressing Cre recombinase under the control of a $\beta$-actin promoter (Lewandoski et al. 1997), resulting in deletion of the sequences between the two loxP sites, including the major transcriptional start, the first exon (containing the DM domain), Pgk-neo, and part of the first intron. The resulting deletion allele is called Dmrt1 $1^{-}$. (B) Genotyping of Dmrt1 alleles. PCR of genomic DNA from wild-type $D \mathrm{mrt1}^{+/+}$, hetero-

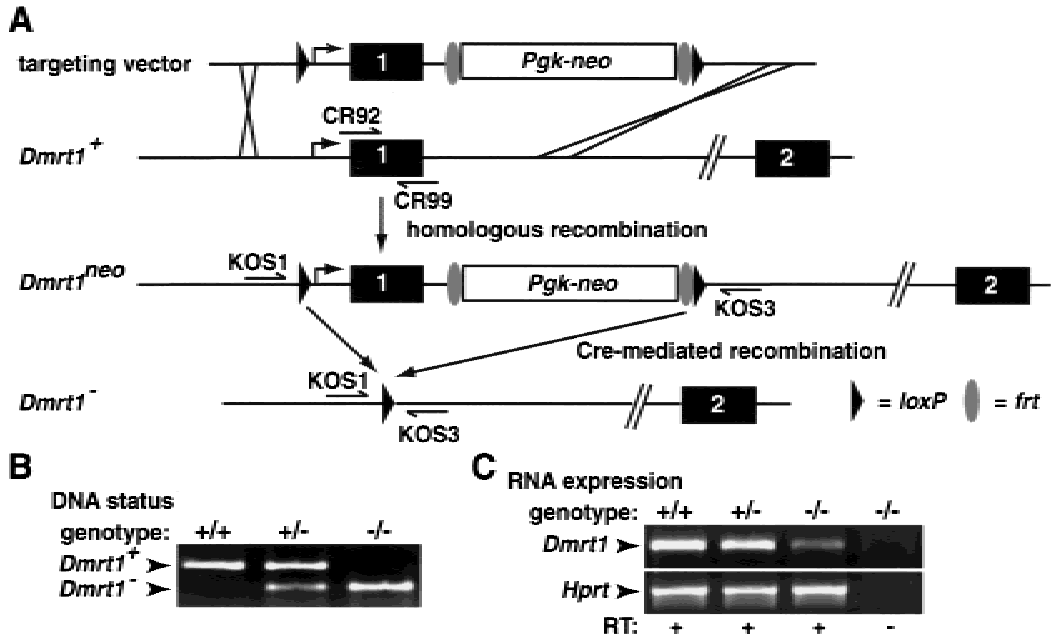
zygous Dmrt1 $1^{+-}$and homozygous Dmrt1 ${ }^{-/-}$animals is shown. For each animal, PCR reactions were run to test for each allele (CR92/CR99 to detect Dmrt $1^{+}$, and KOS1/KOS3 to detect $D m r t 1^{-}$), and the products were mixed and resolved by gel electrophoresis. (C) RT-PCR of Dmrt1 mRNA. RT-PCR of E13.5 testis mRNA was performed using primers from exons 3 and 4, $3^{\prime}$ to the region deleted by the Dmrt1 $1^{-}$mutation (CR132/CR133; see Materials and Methods). Hprt mRNA is a positive control. 

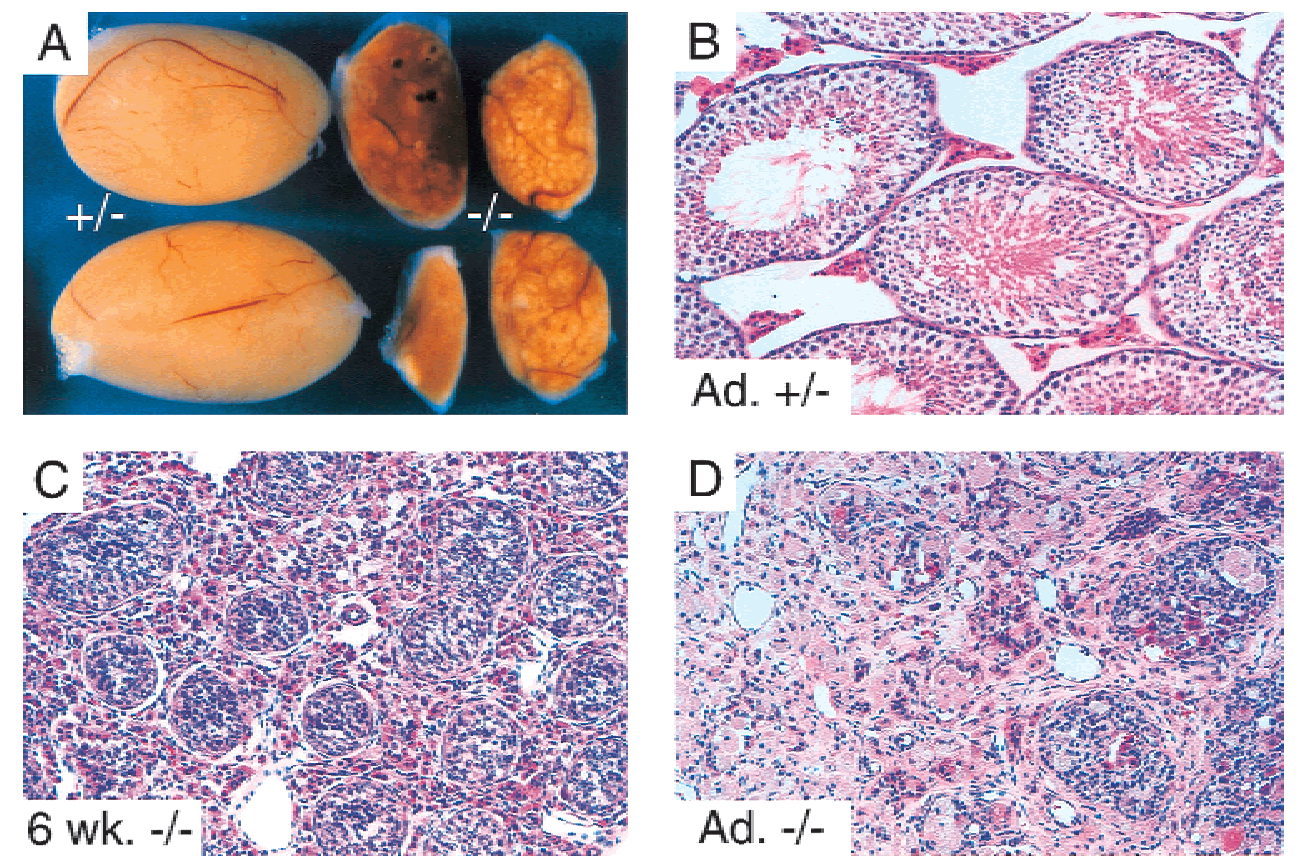

Figure 2. Dmrt1 mutant testes are severely dysmorphic. (A) Adult testis size is reduced in Dmrt1 ${ }^{-/-}$testes (two large testes at left) relative to $D m r t 1^{+/-}$(four small testes at right). Testes are from 10-month-old adults. $(B-D)$ Sections of $D m r t 1^{+/-}$and $D m r t 1^{-/-}$testes stained with hematoxylin and eosin. (B) Adult (16 weeks postpartum) Dmrt1 ${ }^{+/-}$testis, showing normal morphology. (C) Dmrt1 $1^{-/-}$testis at $6 \mathrm{wk}$ post partum. Seminiferous tubules are present and contain immature Sertoli cells, but are devoid of germ cells. There are numerous Leydig cells. (D) Example of adult (16 weeks postpartum) Dmrt1 ${ }^{-1-}$ testis. Small numbers of seminiferous tubules are separated by moderate numbers of interstitial cells, some undergoing vacuolation and fatty degeneration. There is extensive infiltration by cells that often contain light brown pigment (ceroid/lipofuscin). These are considered to be of macrophage and/or interstitial cell origin. Degenerating seminiferous tubules are attenuated and contain variable numbers of immature Sertoli cells, foamy macrophages, and as yet unidentified large eosinophillic cells, but are devoid of identifiable spermatogonia and spermatids.

duced germ cell proliferation. The germ cells still present at P10 remain in the center of the seminiferous tubules, indicating that Dmrt1 is required for the germ cell movements that occur around P7 (see also below). In contrast to $D m r t 1^{+/-}$(Fig. 3C), no meiotic germ cells are evident in the Dmrt1 ${ }^{-1-}$ testis (Fig. 3D).

By P14, germ cells are absent from the Dmrt1 $1^{-/-}$mutant testis and the seminiferous tubules, which are filled with abundant immature Sertoli cells, lack a lumenal space (Fig. 3E,F). This morphology is quite distinct from the hollow tubules containing normal numbers of differentiated Sertoli cells that are typical of other mutants lacking germ cells, such as c-kit (Fig. 3G) or Dhh (Bitgood et al. 1996). In addition, Sertoli cells appear to overproliferate in Dmrt1 $1^{-/-}$mutants. At this stage, the testes of Dmrt1 $1^{-1-}$ and c-kit mutants are approximately the same size and contain similar densities of seminiferous tubules (data not shown). However, the number of Sertoli cells in each cross section of seminiferous tubule is elevated in $\mathrm{Dmrt}^{-1^{--}}$relative to either $\mathrm{Dmrt1} 1^{+/-}$or c-kit (Fig. 3E-G).

The seminiferous tubule morphology we observe in Dmrt $1^{-1-}$ mice resembles phenotypes reported in human infants with deletions of 9p24.3 in several respects. Although detailed histology has only been reported for a small number of human $9 \mathrm{p}$ deletion cases, several features have been noted that are similar to the Dmrt1 ${ }^{-/-}$ phenotype. These features include reduced testis size (Ogata et al. 1997; Guioli et al. 1998), immature Sertoli cell morphology (Ion et al. 1998), germ cells absent or greatly reduced in number (Hoo et al. 1989; Veitia et al. 1997; Ion et al. 1998) and seminiferous tubules disorganized or lacking a central lumen (Veitia et al. 1997; Ion et al. 1998). These phenotypic similarities to Dmrt1 $1^{-/}$mutants suggest that reduced DMRT1 expression may be at least partly responsible for the defective testis differentiation caused by distal 9p deletions in humans. A direct comparison of human and mouse phenotypes is not possible currently, as extensive searches have failed to identify point mutations in human DMRT1 (Raymond et al. 1999b; Calvari et al. 2000; Ottolenghi et al. 2000). In addition to DMRT1, 9p deletions may remove other genes involved in testis development. However, no correlation is apparent between the size of $9 \mathrm{p}$ deletions and the severity of the resulting phenotype. Thus, if testis defects resulting from $9 \mathrm{p}$ hemizygosity are caused by combined loss of Dmrt1 and another gene on $9 p$, the two genes must be tightly linked. The 9p23-9p24 region contains several other DM domain genes (Ottolenghi et al. 2000; C.S. Raymond, J.R. Kettlewell, and D. Zarkower, unpubl.). It will be important to determine whether these or other genes affected by $9 \mathrm{p}$ deletions also are required for testis development. 
Raymond et al.
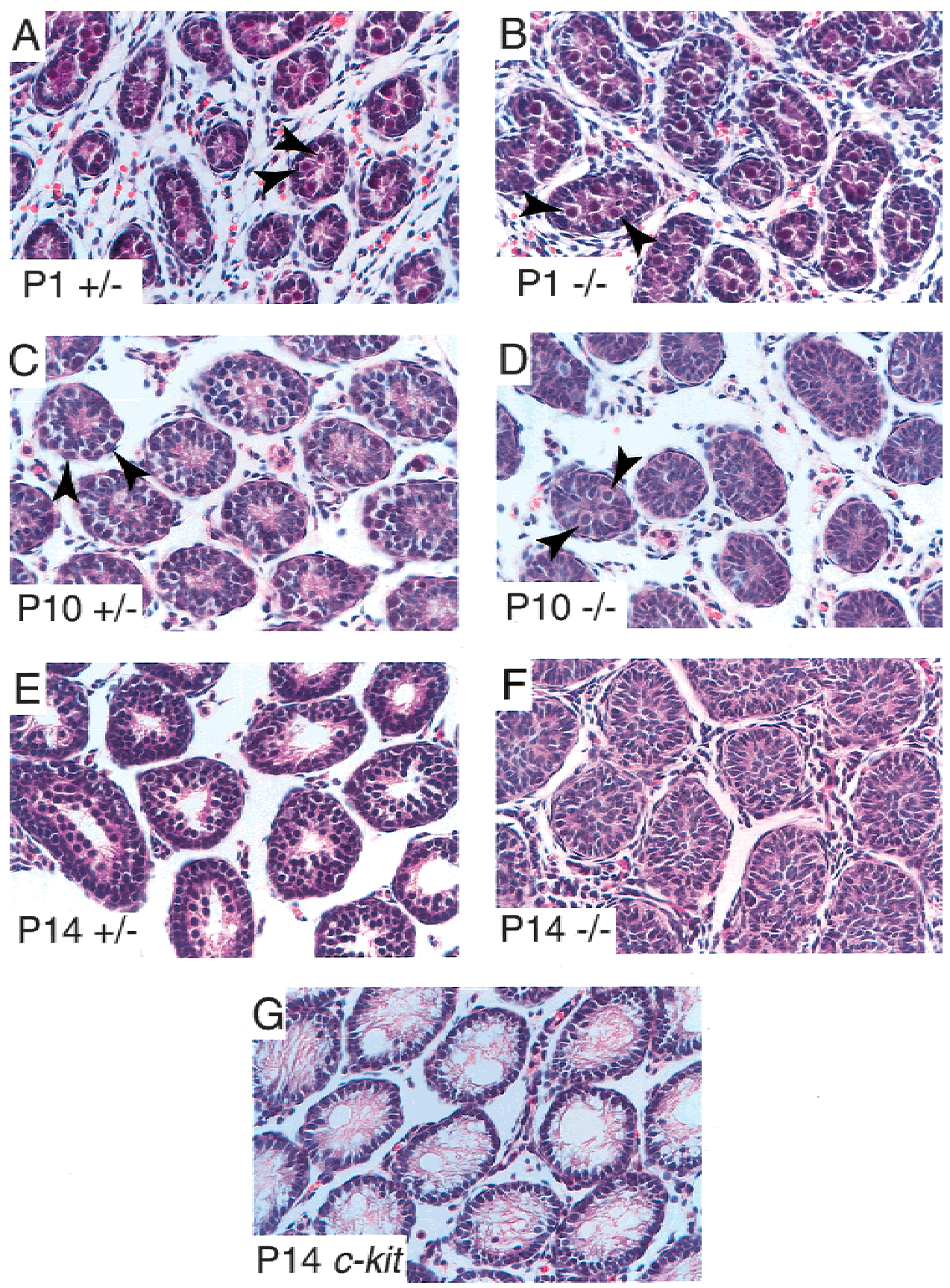

Figure 3. Germ cell death and Sertoli cell over-proliferation in Dmrt1 mutant testes. Sections of Dmrt1 $1^{+/-}$and $D m r t 1^{-/-}$testes of littermates stained with hematoxylin and eosin. (A) P1 Dmrt1 ${ }^{+/-}$testis, showing seminiferous tubules with Sertoli cells (small dark blue nuclei) around periphery, and germ cells (larger round red nuclei; arrowheads) in center. (B) Section of P1 Dmrt1 ${ }^{-/-}$testis, with normal morphology. Germ cells are present in normal numbers (arrowheads). (C) P10 Dmrt1 $1^{+-}$testis. Germ cells have migrated to the periphery (arrowheads). Meiosis has begun and differentiating germ cells (round dark blue nuclei) are visible in some tubules. (D) P10 Dmrt $1^{-/-}$testis. Sertoli cells have begun to over-proliferate. Germ cells are nearly absent, and the few remaining germ cells have failed to migrate to the periphery of the seminiferous tubules (a few germ cells are visible in this section; two are indicated by arrowheads). No meiosis is detectable. (E) P14 Dmrt1 ${ }^{+/-}$testis, showing meiotic germ cells (round dark blue nuclei) within seminiferous tubules. (F) P14 Dmrt1 $1^{-/-}$testis. Immature Sertoli cells are present and have overproliferated, whereas germ cells are absent. (G) P14 c-kit ${ }^{W / W-v}$ mutant testis. Germ cells are absent, as in Dmrt1 $1^{-/-}$testis, but differentiated Sertoli cells are present in normal numbers.

\section{Dynamic expression of Dmrt1 protein}

Dmrt1 mRNA is expressed both in germ cells and in Sertoli cells (Raymond et al. 1999a). Thus, the germ cell death caused by mutation of Dmrt1 could reflect either a defect in the germ cells themselves or a defect in Sertoli cells, which promote germ cell survival and differentiation (Rassoulzadegan et al. 1993; Bitgood et al. 1996). To 
compare Dmrt1 protein expression with Dmrt1 mRNA expression, we generated an antibody against the C-terminal portion of the protein. Immunohistochemistry reveals that in the embryonic testis Dmrt1 protein accumulates primarily in Sertoli cell nuclei, with little or no expression detectable in germ cells (Fig. 4A). Starting at $\mathrm{P} 1, \mathrm{Dmrt1}$ levels rise in germ cells and reach high levels by P7, just before meiosis begins (Fig. 4B-D). The similar timing of increased Dmrt1 expression in germ cells and the onset of germ cell death in the Dmrt1 $1^{-/}$mutant testis suggests a possible cell-autonomous function for Dmrt1 in maintaining the germ line. From P7 through adult stage, Dmrt1 protein is present in Sertoli cells and undifferentiated germ cells, but not in differentiating germ cells (Fig. 4E; data not shown). In adult testis, Dmrt1 is expressed in Sertoli cells in all regions of the seminiferous tubules, but is expressed dynamically in premeiotic germ cells (spermatogonia), with high expression only in regions of the seminiferous tubule that are early in the spermatogenic cycle (Fig. 4G). This further suggests that Dmrt1 may play a role in pre-meiotic germ cells, for example, regulating entry to meiosis or controlling the mitotic cell cycle. The antibody also confirms that no Dmrtl protein is detectable in Dmrt1 $1^{-/-}$testes, demonstrating that this is a null allele (Fig. 4F).

\section{Failure of Sertoli cell differentiation in $\mathrm{Dmrt1}^{-/-}$testes}

Dmrt1 ${ }^{-/}$Sertoli cells overproliferate, fail to adopt a differentiated morphology, and then die postnatally. To characterize these phenotypes further, we examined expression of several Sertoli cell markers. Prior to P7, no defects were apparent. For example, the early marker Gata-4 is expressed normally in Dmrt1 $1^{-/-}$Sertoli cells during embryonic and early postnatal development (Fig. $5)$, as are other early testis markers, including Dhh, Ptch2, and Mis (data not shown). The failure of germ cell migration in Dmrt1 $1^{-/-}$at P7 is clearly visible in sections stained for Gata-4, with most Dmrt $1^{-/-}$germ cells failing to move from the center of the tubule to the margin (Gata-4 negative cells; Fig. 5B). This may result from defects in the germ cells, the Sertoli cells, or both, and may reflect a failure of Sertoli/germ cell interaction. At P14, Gata-4 levels have decreased in $\mathrm{Dmrt1}^{+/-}$, but remain high in Dmrt1 $1^{-/-}$Sertoli cells. The persistence of Gata-4 expression in Dmrt1 ${ }^{-/-}$Sertoli cells may reflect a cell-autonomous defect. Alternatively, it may result from absence of germ cell-dependent regulation, as Gata-4 expression also persists in the Sertoli cells of $c$-kit mutant testes, which also lack germ cells (Fig. 5).

Expression of the later Sertoli cell marker Gata-1 also is abnormal in Dmrt1 ${ }^{-1-}$ testes (Fig. 6). Gata-1 normally is expressed in Sertoli cells from about P10, but expression is delayed and reduced, although not absent, in Dmrt1 $1^{-/}$mutants (Fig. 6), which further confirms the failure of Sertoli cells to complete differentiation in the Dmrt1 $1^{-/}$testis. Gata-1 expression in adult Sertoli cells is dependent on the stage of the spermatogenic cycle (Yomogida et al. 1994; data not shown). It will be of interest to determine whether the cyclical expression of Dmrt1 in spermatogonia and of Gata-1 in the adjacent Sertoli cells are functionally related.

Here we have genetically tested the role of Dmrt1 in mammalian sexual development. We find that murine Dmrt1 is necessary in the male gonad for survival and differentiation of both somatic and germ-line cells. Sertoli cell morphology and gene expression are abnormal in Dmrt1 $1^{-/}$and the phenotype of the mutant testis differs from that of other mutants simply lacking germ cells. Thus, the defects we observe must be caused at least in part by a failure of Sertoli cell differentiation. The loss of germ cells in Dmrt1 $1^{-/-}$may be an indirect effect of Sertoli cell inadequacy or a cell-autonomous defect, possibilities that are currently being tested by cell-specific targeting.
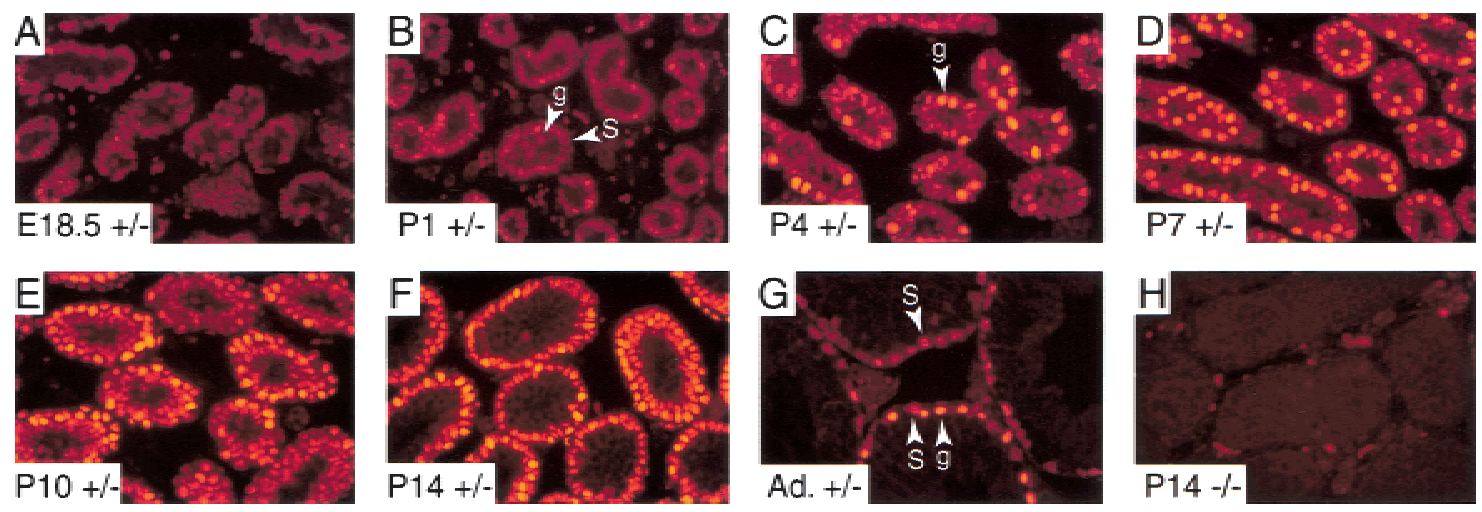

Figure 4. Dmrt1 protein expression. Immunofluorescence of testis sections stained with anti-Dmrt1 antibody. (A) E18.5 testis. Expression is detectable in Sertoli cells and not in germ cells. (B) P1 testis. Expression is detectable Sertoli cells (S) and in some germ cells (g). (C) P4 testis. Expression is detectable in Sertoli cells and becoming strong in most germ cells (g). (D) P7 testis. Expression continues in Sertoli and has become strong in all germ cells. (E) P10 testis. Meiosis has begun. Expression is detectable in Sertoli cells and undifferentiated germ cells (spermatogonia) only. $(F)$ P14 testis. All Sertoli cells and all undifferentiated germ cells express Dmrt1. $(G)$ Sixteen-week-old adult testis. All Sertoli cells (S) express Dmrt1, but spermatogonia (g) express Dmrt1 only in regions early in the spermatogenic cycle (bottom tubule but not the top tubule, which is later in the cycle). (H) P14 Dmrt1 ${ }^{-/-}$testis. No Dmrt1 expression is detectable. Brightly autofluorescent interstitial cells in this and other panels are blood cells. 

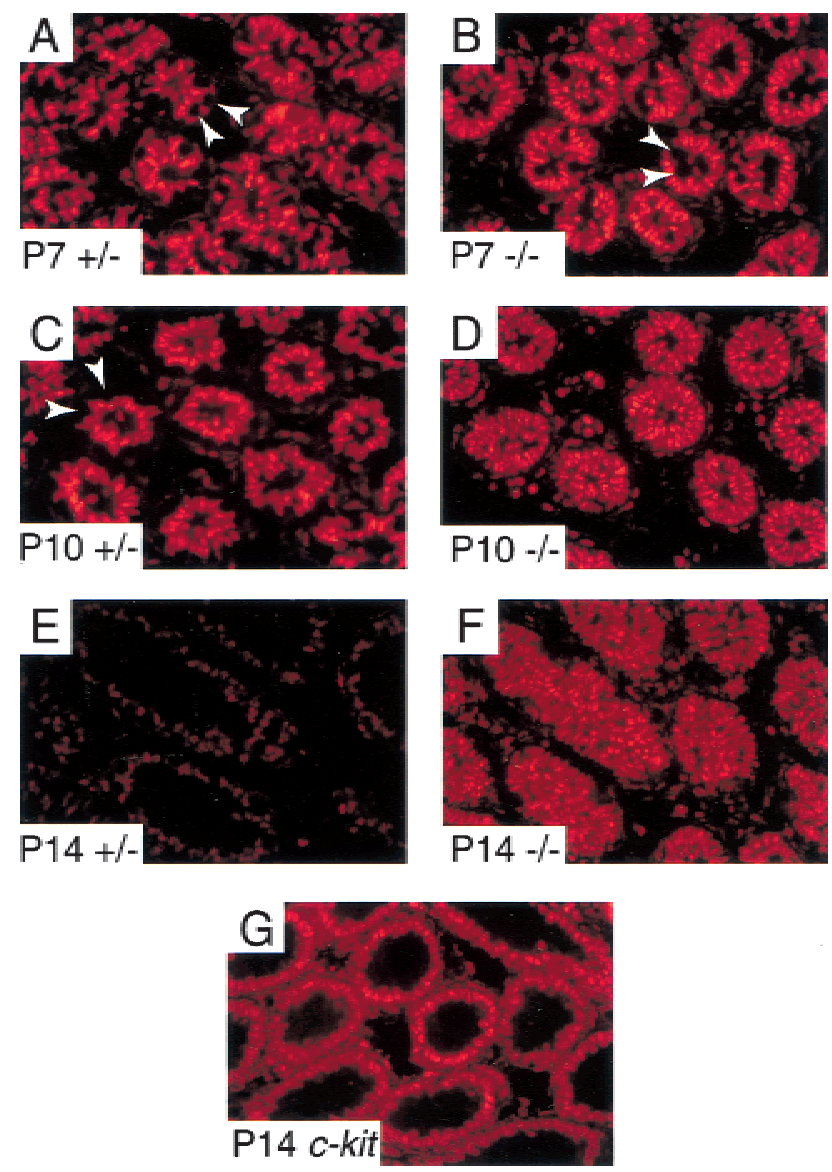

Figure 5. Gata-4 expression persists in $D m r t 1^{-/-}$mutant Sertoli cells. Immunofluorescence of testis sections stained with Gata-4 antibody. Genotype and developmental stage are indicated. (A) P7 Dmrt1 ${ }^{+/-}$testis. Sertoli cells strongly express Gata-4 and germ cells do not. Many germ cells have migrated to periphery of seminiferous tubules (arrowheads). (B) P7 Dmrt1 $1^{-/-}$ testis, Gata-4 expression is normal in Sertoli cells. Most germ cells have failed to migrate to the periphery of the seminiferous tubules and remain in the center (arrowheads). (C) P10 Dmrt1 ${ }^{+/}$ testis. Sertoli cells continue to express high levels of Gata-4. All germ cells are at periphery of seminiferous tubules (arrowheads). (D) P10 Dmrt1 $1^{-/-}$testis. Sertoli cells express high levels of Gata-4 and have begun to overproliferate, and germ cells are nearly absent. (E) P14 Dmrt1 $1^{+-}$testis. Gata-4 expression has decreased in Sertoli cells. (F) P14 Dmrt1 $1^{-/-}$testis. Sertoli cells continue to express high levels of Gata- 4 and to proliferate. Germ cells are absent. (G) P14 c-kit ${ }^{W / W-v}$ mutant testis. Sertoli cells have normal morphology (see Fig. 2G) but express high levels of Gata-4, indicating that germ cells are required for down-regulation of Gata-4 in Sertoli cells.

\section{How similar are mouse and human?}

The defects we have observed in Dmrt1 ${ }^{-1-}$ mutant mice resemble those in humans with distal $9 \mathrm{p}$ deletions (Crocker et al. 1988; Ogata et al. 1997; Ion et al. 1998), with two important differences. First, in mouse, Dmrt1 is recessive, whereas human $9 \mathrm{p}$ deletions in some cases are haploin sufficient for testis differentiation. There are several possible explanations for this difference, which are not mutually exclusive. First, there may be an inherent difference in dose sensitivity in the pathway(s) responsible, because other genes required for testis development are more dose sensitive in human than in mouse (Kreidberg et al. 1993; Swain et al. 1998). Second, genetic background may be important. Human 9p hemizygosity causes testis defects of variable severity and is incompletely penetrant, even when the critical region for testis development is removed by large deletions (Veitia et al. 1998, and references therein), suggesting that background effects may be significant. (In addition, the degree
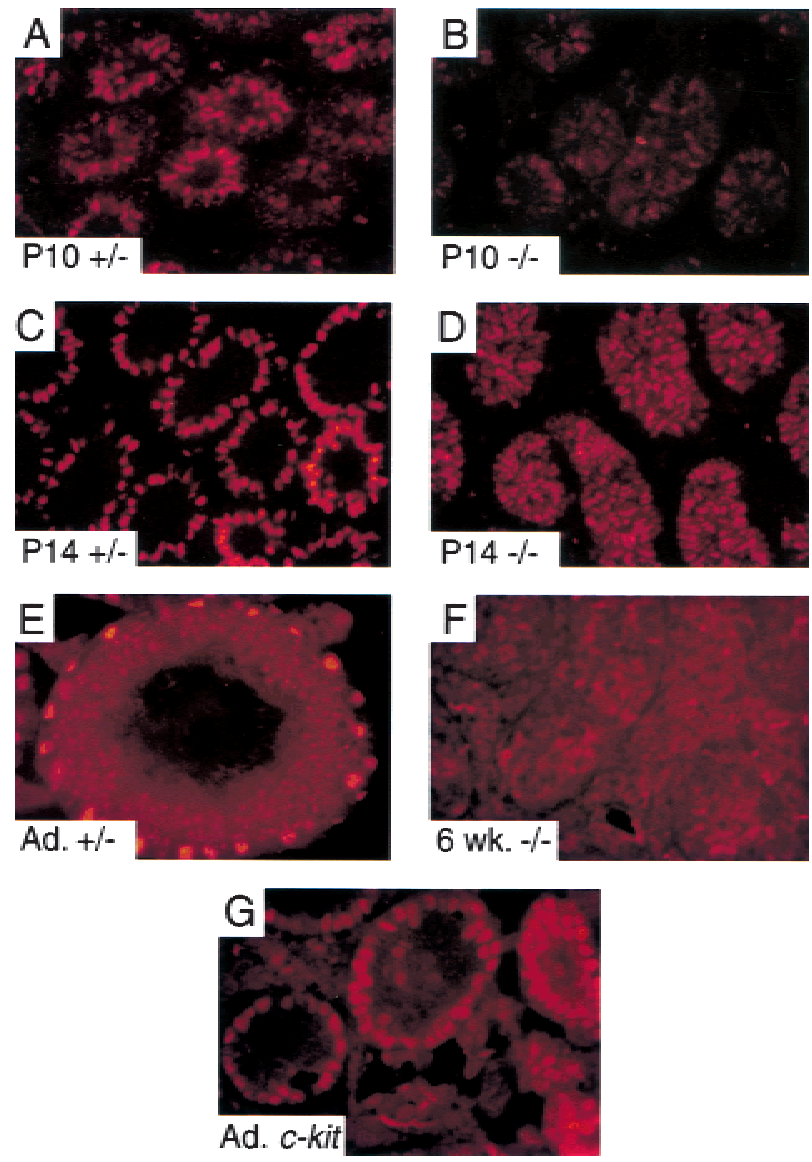

Figure 6. Gata-1 expression is delayed and reduced in Dmrt1 mutant Sertoli cells. Immunofluorescence of testis sections stained with Gata-1 antibody. (A) P10 Dmrt1 ${ }^{+/-}$testis. Most Sertoli cells have begun to express Gata-1. (B) P10 Dmrt1-/testis. Gata-1 expression is lower than in heterozygous littermate shown in $A$. (C) P14 Dmrt1 ${ }^{+/-}$testis. Most Sertoli cells express high levels of Gata-1. (D) P14 Dmrt1 ${ }^{-/-}$testis. Most Sertoli cells express some Gata-1, but generally at lower levels than in heterozygous littermate shown in C. (E) Adult (16 weeks post partum) $D m r t 1^{+/-}$testis. Gata-1 expression is strong in Sertoli cells (brightly staining cells spaced around periphery of seminiferous tubule) and also is present in meiotic germ cells. $(F)$ Six-week postnatal $\mathrm{Dmrt1}^{-1-}$ testis. Gata-1 expression has not been maintained, and Sertoli cells express low levels. (Most staining is nonspecific background.) (G) Adult c-kit ${ }^{W / W-v}$ mutant testis. Sertoli cells express high levels of Gata-1, demonstrating that the germ line is not necessary for high-level Gata-1 expression. 
of haploinsufficiency of 9p24.3 in humans may be overestimated, as small deletions with no testis phenotype would go undetected.) Experiments are under way to test whether heterozygous murine Dmrt1 mutants have a phenotype on different genetic backgrounds. Finally, it is possible that $9 \mathrm{p}$ deletions remove an additional gene(s) involved in testis development and thus, although DMRT1 is recessive, combined hemizygosity with another gene(s) can cause defective testis development in $\mathrm{XY}$ individuals retaining a copy of DMRT1.

Another important difference between mouse and human is that some 9p-deleted XY patients have Mullerian duct remnants and feminized external genitalia, whereas, perhaps surprisingly, no defects outside of the gonads have been observed in Dmrt1 ${ }^{-/-}$mice. This finding indicates earlier defects in Sertoli cell function in human than those observed in the Dmrt1 $1^{-/-}$mouse. As discussed above, we cannot yet eliminate the possibility that genetic background effects are obscuring earlier functions in the mouse. However, male-specific DMRT1 mRNA expression occurs at an earlier developmental stage in the human gonad than in mouse (Moniot et al. 2000), and thus DMRT1 might play an earlier role in human testis differentiation than Dmrt1 does in mouse. Birds and reptiles also have male-specific Dmrt1 expression prior to gonad differentiation (Raymond et al. 1999; Smith et al. 1999; Kettlewell et al. 2000), and so Dmrt1 may be required earlier in gonad development in these species as well.

What is the relationship between Dmrt1, dsx, and mab-3?

Of what significance is the similarity of Dmrt1 to the invertebrate sexual regulators $d s x$ and $m a b-3$ ? The data presented here demonstrate that in mammals, as in nematodes and insects, a DM domain transcription factor controls male sexual development. Does this functional similarity imply a close evolutionary relationship between Dmrt1 and the invertebrate sexual regulators? Currently, this question cannot be satisfactorily answered for several reasons. First, comparison of protein sequence alone is not very helpful in this case. Even $d s x$ and mab-3, which perform a number of related biological functions and can be functionally interchangeable, show quite limited sequence similarity, restricted primarily to the DM domain. Of the 12 nematode DM domain genes, the one most similar in sequence to $d s x$ is not mab-3 (C.S. Raymond, W. Yi, and D. Zarkower, unpubl.). We and others have identified several vertebrate DM domain genes, but it is not yet clear whether Dmrt1 is the one most closely related to $d s x$ and mab-3. Not all vertebrate DM domain genes are involved in testis development (Meng et al 1999; J.R. Kettlewell and D. Zarkower, unpubl.). However, other DM domain genes are expressed in the embryonic mouse gonad (J.R. Kettlewell, C.S. Raymond, and D. Zarkower, unpubl.), so it is possible that multiple members of this gene family are involved in vertebrate gonad development. Thus, on the basis of se- quence comparison, one cannot yet conclude that Dmrt1 is the mammalian ortholog of $d s x$ and mab-3.

A second issue confounding the evolutionary question is the fundamentally different biology of mammalian sex determination as compared with that of invertebrates. In worms and flies, sex determination occurs throughout the body, so if $d s x$ and mab-3 are orthologs, they can reasonably be expected to control a number of similar aspects of sexual dimorphism. However, in mammals, sex determination occurs in the embryonic gonad and secreted sex hormones induce sexual dimorphism elsewhere. Thus, there is no a priori expectation that Dmrt1 should regulate yolk protein transcription or control nervous system sexual dimorphism, as $d s x$ and mab-3 do, or that Dmrt1 should function anywhere outside of the gonad.

Confounding the situation further, sex determination evolves rapidly and the role of sex-determining genes can change rapidly. An extreme example is Sry, which plays a pivotal role in mammalian sex determination but does not exist in birds and reptiles. Similarly, Sox 9 appears to play an early sex-determining role in mammals but a later role in testis differentiation in other vertebrates (Kent et al. 1996; Morais da Silva et al. 1996; Oreal et al. 1998; Spotila et al. 1998; Moreno-Mendoza et al. 1999; Western et al. 1999). Nevertheless, given the evolutionary lability of sex-determining genes, it is particularly striking that Dmrt1 has been found in all vertebrates in which it has been sought. Furthermore, Dmrt1 is unique in being expressed very early and sex specifically in the gonad of all classes of vertebrates so far examined, regardless of the sex-determining mechanism used, whether chromosomal or environmental. Determining the evolutionary relationships of $d s x, m a b-3$, and Dmrt1 will require the examination of a greater range of species. What is now clear, however, is that DM domain genes play an essential role in sexual development in at least three phyla and probably in others.

\section{Materials and methods}

Production of $\mathrm{Dmrt1}^{-/-}$mice

A mouse Dmrt1 cDNA fragment containing sequences from exon 1 was used to screen a mouse genomic $\lambda$ phage library from the $129 / \mathrm{Sv}$ J strain (Stratagene), and clones containing promoter sequences were isolated and sequenced to obtain Dmrt1 genomic sequences spanning the first intron. The targeting vector pDZ161 (diagrammed in Fig. 1A) was constructed by the following scheme. A neomycin resistance cassette $(P g k-n e o)$ flanked with Flp recombinase recognition sites (frt sites), with a loxP site 3' to neo (derived from pK-11; gift of E. Meyers, M. Lewandoski, and G. Martin; Meyers et al. 1998), was inserted between the SacI and KpnI sites of pSP73 (Stratagene) to generate pDZ157. 3' to Pgk-neo and the loxP site we inserted, as a ApaI/ XhoI DNA fragment, sequences from the first intron of Dmrt1 (from 342 bp to $2797 \mathrm{bp}$ downstream of exon 1), generated by PCR. 5' to Pgk-neo, we inserted a NotI/EcoRI PCR fragment extending from $3192 \mathrm{bp} 5^{\prime}$ of the Dmrt1 translational start to 342 bp downstream of exon 1 . Finally, we inserted a loxP site and NotI site $481 \mathrm{bp} 5^{\prime}$ of the Dmrt1 translational start $(\sim 300 \mathrm{bp}$ $5^{\prime}$ of the transcriptional start as determined by $5^{\prime}$ RACE and 
cDNA sequences; data not shown). In the resulting vector, the first exon of Dmrt1 is flanked by loxP sites (floxed). The Dmrt1containing portions of pDZ161 were completely sequenced.

pDZ161 was linearized with XhoI and electroporated into ES cells. Two homologous recombinants were identified from 192 G418-resistant colonies by Southern hybridization by use of a DNA probe from intron 1 to screen genomic DNA digested with HindIII. Homologous recombination was confirmed on both ends of the targeted region by PCR with primers from outside of the targeted region paired with primers specific to $\mathrm{pDZ161}$ (data not shown). A targeted ES cell clone containing the floxed allele Dmrt $1^{\text {neo }}$ was injected into C57/B16 blastocysts to generate chimeras. Chimeric males were bred with $\mathrm{C} 57 / \mathrm{Bl} 6$ females to generate heterozygotes carrying $D m r t 1^{\text {neo }}$. Dmrt $1^{+} / D m r t 1^{\text {neo }}$ females were bred with male $\beta$-actin-Cre transgenic mice (gift of M. Lewandoski; Lewandoski et al. 1997) to generate heterozygous Dmrt1 deletion mutants $\left(D m r t 1^{+} / D m r t 1^{-}\right)$. Mating of Dmrt $1^{+} / D m r t 1^{-}$males and females generated homozygous Dmrt1 $1^{-}$mutants. In each litter, all animals were genotyped and assessed for phenotypic sex. To test whether Dmrt1 ${ }^{+/-}$might have testis defects, we tested fertility of $\sim 25$ adult males and performed histological analysis of $\sim 12$ males at different postnatal stages. We observed no defects in either fertility or testis morphology.

\section{Genotyping}

For genotyping, tailclip DNA was amplified for 40 cycles. Chromosomal sex was determined by PCR with primers to the $\mathrm{Y}$ chromosome gene $Z f y$ (below). The wild-type Dmrt1 allele Dmrt $1^{+}$was detected by PCR with CR92/CR99, with an annealing temperature of $55^{\circ} \mathrm{C}$. The floxed allele Dmrtineo was detected by PCR with KOS2/CR127, with an annealing temperature of $65^{\circ} \mathrm{C}$. The deleted Dmrt1 allele Dmrt1 ${ }^{-}$was detected with KOS1/KOS3 with an annealing temperature of $55^{\circ} \mathrm{C}$. PCR with CR92/CR99 contained 10\% DMSO.

\section{Primers}

KOS1 5'-TTCTTGGATGTTCAATCTGTCTC-3'; KOS2 5'-TG CACACGTGCACCCTCGCCATCG-3'; KOS3 5'-TTCTGATT CAGGGAATCTCGCGAC-3'; CR92 5'-CAGCTCCATGGC GAACGACGACACATTCGG-3'; CR99 5'-CTGCAGCGAGC GCATTTGGGCAGC-3'; CR127 5'-CTGCTAAAGCGCATG CTCCAGACTG-3'; CR132 5'-TCAGAGGGACGCATGGTC ATCCAG-3'; CR133 5'-GTGCATCCGGTACTGGGAGCTC AC-3'; ZFYF 5'-CCTATTGCATGGACAGCAGTCTTATG-3'; ZFYR 5'-GACTAGACATGTCTTAACATCTGTCC-3'.

\section{Immunohistochemistry}

Rabbit polyclonal antibodies to Dmrtl were raised against a purified Dmrtl fusion protein containing glutathione-S-transferase (GST) fused to the C-terminal 108 amino acids of Dmrt1. Antiserum was purified and concentrated by a $33 \%$ saturation ammonium sulphate cut, and antibodies to GST were removed by GST-affigel 10 chromotography. The antibody was used at $1: 2000$ dilution with a Cy3-conjugated goat anti-rabbit secondary antibody (Jackson Immunochemicals) at $1: 1000$ dilution.

Gata-1 was detected with a rat monoclonal antibody (Santa Cruz Biotechnology, sc-265) and Gata-4 was detected with a goat monoclonal antibody (Santa Cruz Biotechnology, sc-1237), each at $1: 200$ dilution. Secondary antibodies were Cy3-conjugated rabbit anti-rat or anti-goat (Jackson Immunochemicals) at $1: 1000$ dilution.

\section{Acknowledgments}

We thank Robert Anderson, Electra Coucouvanis, David Largaespada, Carlos Manivel, William Shawlot, and members of the Zarkower and Bardwell laboratories for much valuable advice and assistance, and Electra Coucouvanis and William Shawlot for critical reading of the manuscript. We thank David Largaespada, Mark Lewandoski, Andrew McMahon, and Matthew Scott for providing clones and libraries, Mark Lewandoski for providing Cre transgenic mice, and Sandra Horn, David Largaespada, and the University of Minnesota Mouse Genetics Laboratory for expert technical assistance. This work was supported by the NIH (D.Z, V.J.B, C.S.R, and M.W.M.), the Minnesota Medical Foundation (D.Z. and V.J.B.), the University of Minnesota Graduate School (D.Z. and V.J.B.), and the University of Minnesota Center for Developmental Biology (D.Z.).

The publication costs of this article were defrayed in part by payment of page charges. This article must therefore be hereby marked "advertisement" in accordance with 18 USC section 1734 solely to indicate this fact.

\section{References}

Baker, B.S. and Ridge, K. 1980. Sex and the single cell: On the action of major loci affecting sex determination in Drosophila melanogaster. Genetics 94: 383-423.

Bennett, C.P., Docherty, Z., Robb, S.A., Ramani, P., Hawkins, J.R., and Grant, D. 1993. Deletion 9p and sex reversal. J. Med. Genet. 30: 518-520.

Bitgood, M.J., Shen, L., and McMahon, A.P. 1996. Sertoli cell signaling by Desert hedgehog regulates the male germline. Curr. Biol. 6: 298-304.

Calvari, V., Bertini, V., De Grandi, A., Peverali, G., Zuffardi, O., Ferguson-Smith, M., Knudtzon, J., Camerino, G., Borsani, G., and Guioli, S. 2000. A new submicroscopic deletion that refines the 9p region for sex reversal. Genomics 65: 203-212.

Coschigano, K.T. and Wensink, P.C. 1993. Sex-specific transcriptional regulation by male and female doublesex proteins of Drosophila. Genes \& Dev. 7: 42-54.

Crocker, M., Coghill, S.B., and Cortinho, R. 1988. An unbalanced autosomal translocation $(7 ; 9)$ associated with feminization. Clin. Genet. 34: 70-73.

De Grandi, A., Calvari, V., Bertini, V., Bulfone, A., Peverali, G., Camerino, G., Borsani, G., and Guioli, S. 2000. The expression pattern of a mouse doublesex-related gene is consistent with a role in gonadal differentiation. Mech. Dev. 90:323326.

Erdman, S.E. and Burtis, K.C. 1993. The Drosophila doublesex proteins share a novel zinc finger related DNA binding domain. EMBO J. 12: 527-535.

Flejter, W.L., Fergestad, J., Gorski, J., Varvill, T., and Chandrasekharappa, S. 1998. A gene involved in XY sex reversal is located on chromosome 9, distal to marker D9S1779. Am. J. Hum. Genet. 63: 794-802.

Guioli, S., Schmitt, K., Critcher, R., Bouzyk, M., Spurr, N.K., Ogata, T., Hoo, J.J., Pinsky, L., Gimelli, G., Pasztor, L., et al. 1998. Molecular analysis of 9p deletions associated with XY sex reversal: Refining the localization of a sex-determining gene to the tip of the chromosome. Am. J. Hum. Genet. 63: 905-908.

Hoo, J.J., Salafsky, I.S., and Lin, C.C. 1989. Possible localisation of a recessive testis forming gene on 9p24. Am. J. Hum. Genet. (Suppl.) 45: A73.

Ion, R., Telvi, L., Chaussain, J.L., Barbet, J.P., Nunes, M., Safar, A., Rethore, M.O., Fellous, M., and McElreavey, K. 1998. Failure of testicular development associated with a rear- 
rangement of 9p24.1 proximal to the SNF2 gene. Hum. Genet. 102: 151-156.

Kent, J., Wheatley, S.C., Andrews, J.E., Sinclair, A.H., and Koopman, P. 1996. A male-specific role for SOX9 in vertebrate sex determination. Development 122: 2813-2822.

Kettlewell, J.R., Raymond, C.S., and Zarkower, D. 2000. Temperature-dependent expression of turtle Dmrt1 prior to sexual differentiation. Genesis 26: 174-178.

Kreidberg, J.A., Sariola, H., Loring, J.M., Maeda, M., Pelletier, J., Housman, D., and Jaenisch, R. 1993. WT-1 is required for early kidney development. Cell 74: 679-691.

Lewandoski, M., Meyers, E.N., and Martin, G.R. 1997. Analysis of Fgf8 gene function in vertebrate development. Cold Spring Harb. Symp. Quant. Biol. 62: 159-168.

Meng, A., Moore, B., Tang, H., Yuan, B., and Lin, S. 1999. A Drosophila doublesex-related gene, terra, is involved in somitogenesis in vertebrates. Development 126: 1259-1268.

Meyers, E.N., Lewandoski, M., and Martin, G.R. 1998. An Fgf8 mutant allelic series generated by Cre- and Flp-mediated recombination. Nat. Genet. 18: 136-141.

Moniot, B., Berta, P., Scherer, G., Sudbeck, P., and Poulat, F. 2000. Male specific expression suggests role of DMRT1 in human sex determination. Mech. Dev. 91: 323-325.

Morais da Silva, S., Hacker, A., Harley, V., Goodfellow, P., Swain, A., and Lovell-Badge, R. 1996. Sox9 expression during gonadal development implies a conserved role for the gene in testis differentiation in mammals and birds. Nat. Genet. 14: 62-68.

Moreno-Mendoza, N., Harley, V.R., and Merchant-Larios, H. 1999. Differential expression of SOX9 in gonads of the sea turtle Lepidochelys olivacea at male- or female-promoting temperatures. J. Exp. Zool. 284: 705-710.

Nanda, I., Shan, Z., Schartl, M., Burt, D.W., Koehler, M., Nothwang, H., Grutzner, F., Paton, I.R., Windsor, D., Dunn, I., et al. 1999. 300 million years of conserved synteny between chicken $\mathrm{Z}$ and human chromosome 9. Nat. Genet. 21: 258-259.

Ogata, T., Muroya, K., Matsuo, N., Hata, J., Fukushima, Y., and Suzuki, Y. 1997. Impaired male sex development in an infant with molecularly defined partial 9p monosomy: Implication for a testis forming gene(s) on 9p. J. Med. Genet. 34: 331-334.

Oreal, E., Pieau, C., Mattei, M.G., Josso, N., Picard, J.Y., CarreEusebe, D., and Magre, S. 1998. Early expression of AMH in chicken embryonic gonads precedes testicular SOX9 expression. Dev. Dyn. 212: 522-532.

Ottolenghi, C., Veitia, R., Quintana-Murci, L., Torchard, D., Scapoli, L., Souleyreau-Therville, N., Beckmann, J., Fellous, M., and McElreavey, K. 2000. The region on 9p associated with $46, X Y$ sex reversal contains several transcripts expressed in the urogenital system and a novel doublesex-related domain. Genomics 64: 170-178.

Rassoulzadegan, M., Paquis-Flucklinger, V., Bertino, B., Sage, J., Jasin, M., Miyagawa, K., van Heyningen, V., Besmer, P., and Cuzin, F. 1993. Transmeiotic differentiation of male germ cells in culture. Cell 75: 997-1006.

Raymond, C.S., Shamu, C.E., Shen, M.M., Seifert, K.J., Hirsch, B., Hodgkin, J., and Zarkower, D. 1998. Evidence for evolutionary conservation of sex-determining genes. Nature 391: 691-695.

Raymond, C.S., Kettlewell, J.R., Hirsch, B., Bardwell, V.J., and Zarkower, D. 1999a. Expression of Dmrt1 in the genital ridge of mouse and chicken embryos suggests a role in vertebrate sexual development. Dev. Biol. 215: 208-220.

Raymond, C.S., Parker, E.D., Kettlewell, J.R., Brown, L.G., Page, D.C., Kusz, K., Jaruzelska, J., Reinberg, Y., Flejter, W.L., Bardwell, V.J., Hirsch, B., Zarkower, D. 1999b. A region of human chromosome 9p required for testis development contains two genes related to known sexual regulators. Hum. Mol. Genet. 8: 989-996.

Shen, M.M. and Hodgkin, J. 1988. mab-3, a gene required for sex-specific yolk protein expression and a male-specific lineage in C. elegans. Cell 54: 1019-1031.

Smith, C.A., McClive, P.J., Western, P.S., Reed, K.J., and Sinclair, A.H. 1999. Conservation of a sex-determining gene. Nature 402: 601-602.

Spotila, L.D., Spotila, J.R., and Hall, S.E. 1998. Sequence and expression analysis of WT1 and Sox9 in the red-eared slider turtle, Trachemys scripta. J. Exp. Zool. 281: : 417-427.

Swain, A., Narvaez, V., Burgoyne, P., Camerino, G., and LovellBadge, R. 1998. Dax1 antagonizes Sry action in mammalian sex determination. Nature 391: 761-767.

Veitia, R., Nunes, M., Brauner, R., Doco-Fenzy, M., Joanny-Flinois, O., Jaubert, F., Lortat-Jacob, S., Fellous, M., and McElreavey, K. 1997. Deletions of distal 9p associated with $46, \mathrm{XY}$ male to female sex reversal: Definition of the breakpoints at 9p23.3-p24.1. Genomics 41: 271-274.

Veitia, R.A., Nunes, M., Quintana-Murci, L., Rappaport, R., Thibaud, E., Jaubert, F., Fellous, M., McElreavey, K., Goncalves, J., Silva, M., et al. 1998. Swyer syndrome and 46,XY partial gonadal dysgenesis associated with $9 \mathrm{p}$ deletions in the absence of monosomy-9p syndrome. Am. J. Hum. Genet. 63: 901-905.

Villella, A. and Hall, J.C. 1996. Courtship anomalies caused by doublesex mutations in Drosophila melanogaster. Genetics 143: 331-344.

Western, P.S., Harry, J.L., Graves, J.A., Sinclair, A.H. 1999. Temperature-dependent sex determination: Upregulation of SOX9 expression after commitment to male development. Dev. Dyn. 214: 171-177.

Yi, W. and Zarkower, D. 1999. Similarity of DNA binding and transcriptional regulation by Caenorhabditis elegans MAB-3 and Drosophila melanogaster DSX suggests conservation of sex determining mechanisms. Development 126: 873-881.

Yi, W., Ross, J.M., and Zarkower, D. 2000. mab-3 is a direct tra-1 target gene regulating diverse aspects of C. elegans male sexual development and behavior. Development (in press).

Yomogida, K., Ohtani, H., Harigae, H., Ito, E., Nishimune, Y., Engel, J.D., and Yamamoto, M. 1994. Developmental stageand spermatogenic cycle-specific expression of transcription factor GATA-1 in mouse Sertoli cells. Development 120: $1759-1766$. 


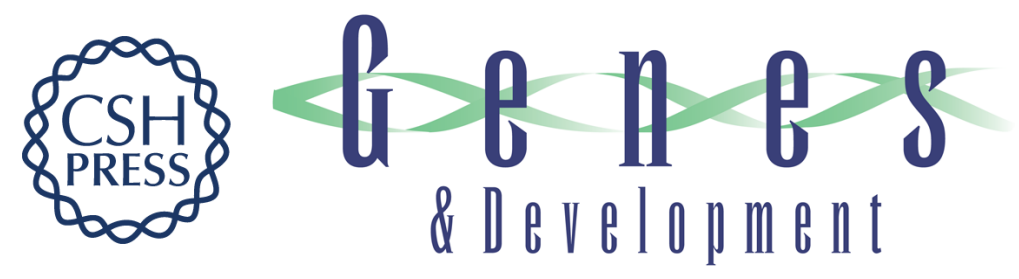

\section{Dmrt1, a gene related to worm and fly sexual regulators, is required for mammalian testis differentiation}

Christopher S. Raymond, Mark W. Murphy, M. Gerard O'Sullivan, et al.

Genes Dev. 2000, 14:

Access the most recent version at doi:10.1101/gad.834100

References This article cites 39 articles, 10 of which can be accessed free at: http://genesdev.cshlp.org/content/14/20/2587.full.html\#ref-list-1

License

Email Alerting

Receive free email alerts when new articles cite this article - sign up in the box at the top Service right corner of the article or click here.

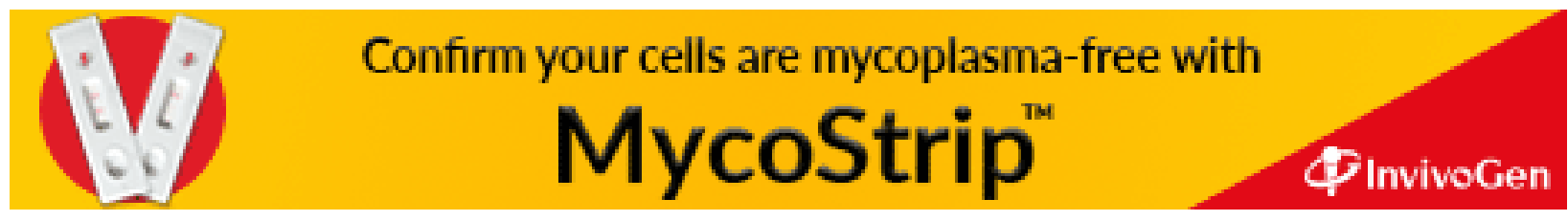

